OPEN ACCESS

Edited by:

Volker Rasche,

University of UIm, Germany

Reviewed by:

J. Marc Simard,

University of Maryland, Baltimore,

United States

Qi Li,

The First Affiliated Hospital of Chongqing Medical University, China

${ }^{*}$ Correspondence: Ruiting Zhang zhangruiting@zju.edu.cn

Specialty section

This article was submitted to Applied Neuroimaging,

a section of the journal

Frontiers in Neurology

Received: 23 August 2021 Accepted: 06 December 2021 Published: 11 January 2022

Citation:

Zhang $X$, Huang $P$ and Zhang $R$ (2022) Evaluation and Prediction of Post-stroke Cerebral Edema Based

on Neuroimaging.

Front. Neurol. 12:763018. doi: 10.3389/fneur.2021.763018

\section{Evaluation and Prediction of Post-stroke Cerebral Edema Based on Neuroimaging}

\author{
Xiaocheng Zhang, Peiyu Huang and Ruiting Zhang* \\ Department of Radiology, School of Medicine, The Second Affiliated Hospital of Zhejiang University, Hangzhou, China
}

Cerebral edema is a common complication of acute ischemic stroke that leads to poorer functional outcomes and substantially increases the mortality rate. Given that its negative effects can be reduced by more intensive monitoring and evidence-based interventions, the early identification of patients with a high risk of severe edema is crucial. Neuroimaging is essential for the assessment and prediction of edema. Simple markers, such as midline shift and hypodensity volume on computed tomography, have been used to evaluate edema in clinical trials; however, advanced techniques can be applied to examine the underlying mechanisms. In this study, we aimed to review current imaging tools in the assessment and prediction of cerebral edema to provide guidance for using these methods in clinical practice.

\section{Keywords: ischemic stroke, edema, mechanism, imaging evaluation, predictors}

\section{INTRODUCTION}

Cerebral edema is a severe complication of acute ischemic stroke; it results in poorer functional outcomes and significantly increases the rate of mortality. During ischemia, excessive fluid accumulates in the intracellular or extracellular spaces of the brain because of the failure of energydependent ion transport (1-3) and the destruction of the blood-brain barrier (BBB) (4-6), which leads to tissue swelling and the elevation of intracranial pressure. Cerebral edema can appear several hours after ischemia and may progress over the first few days of stroke onset (7).

Patients with mild to moderate edema can be treated with medication $(3,8,9)$. However, for those with malignant edema (ME), the mortality rate can increase up to $80 \%$ with conservative treatment (10-12). Timely surgical treatment by early decompressive craniectomy is recommended to reduce mortality $(9,13-15)$. Thus, the accurate assessment and early prediction of edema can benefit patients by more intensive monitoring and evidence-based interventions.

Neuroimaging examination is essential for the assessment of edema. Midline shift (MLS) has long been established as a marker of severe edema and is known to correlate with clinical deterioration (16-18). However, MLS is insensitive to mild to moderate edema and is thus an unsuitable index for monitoring the condition of patients. Recently, new methods, such as cerebrospinal fluid (CSF) displacement $(19,20)$ and net water uptake (NWU) $(12,21)$, have been developed to quantify brain edema at an early stage. Furthermore, magnetic resonance imaging 


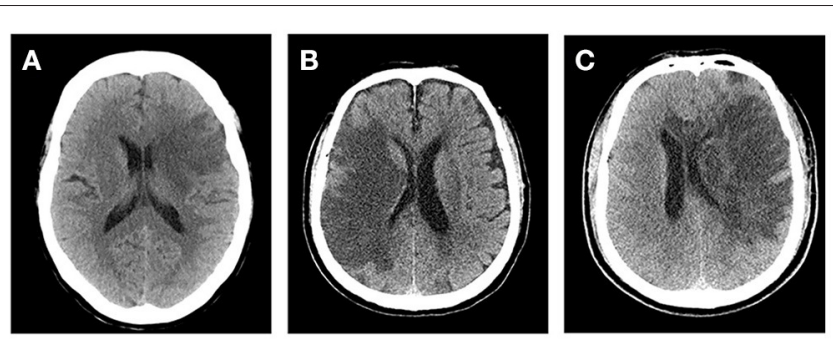

FIGURE 1 | Cerebral edema grades. (A) Left frontal lobe and basal ganglia brain swelling, $<1 / 3$ of the hemisphere. (B) Right frontal and parietal lobe brain swelling, $>1 / 3$ of the hemisphere and without midline shift (MLS). (C) Left cerebral hemisphere swelling, $>1 / 3$ of the hemisphere with MLS.

(MRI) can distinguish cytotoxic edema from ionic edema and vasogenic edema $(22,23)$, and advanced MRI techniques, such as diffusion tensor imaging, can detect subtle structural changes in brain edema (24). These new methods can be used to quantify less severe edema and may serve as early imaging markers in clinical practice.

Imaging is important in the prediction of edema. Previous research has shown that infarct volume, collateral status, and CSF volume (CSV), among other factors, are closely related to the development of edema $(11,18,25,26)$. However, the predictive values of these indicators often vary across studies $(18,27)$; moreover, the optimal timing and modality of imaging exams are also under debate.

There have been numerous reviews on post-stroke edema, of which most have focused on the mechanisms of edema with an emphasis on scientific discoveries rather than on clinical applications. In this review, we briefly discuss the mechanisms of post-stroke edema and focus more on current edema assessment methods and neuroimaging predictors.

Our aim was to provide a comprehensive review of imaging tools for the management of edema and provide guidance for clinical practice.

\section{MECHANISM OF EDEMA}

Traditionally, cerebral edema after an ischemic stroke includes cytotoxic edema, ionic edema, and vasogenic edema (7). These three processes occur in sequence and are closely interrelated. Cytotoxic edema is the earliest manifestation of brain hydromineral disturbance as a result of changes in ion channel and transporter (e.g., $\mathrm{Na}^{+}-\mathrm{K}^{+}-2 \mathrm{Cl}^{-}$cotransporter and $\mathrm{Na}-\mathrm{H}$ exchangers) activity during a stroke event $(3,28-31)$. It attracts ions and water into neurons or astrocytes, which causes intracellular water accumulation and extracellular space reduction without increasing brain tissue volume. Because of the changes in ion concentrations on both sides of the BBB, new gradients are formed; this generates a driving force for an influx of water and ion across the intact BBB into the depleted extracellular space, resulting in ionic edema (32-34). Ischemia can also activate inflammatory mediators and increase oxidative stress $(35,36)$, both of which lead to BBB disruption. This event allows plasma proteins and other macromolecules to pass through the $\mathrm{BBB}$ from the intravascular space into brain tissue, which further aggravates water influx and results in vasogenic edema. Recently, studies have shown that post-stroke cerebral edema can also be driven by CSF influx through perivascular spaces $(37,38)$. Although this has not been confirmed clinically, the related mechanisms underlying the structural and functional abnormalities of the brain's glymphatic system following stroke have gathered the interest of researchers.

\section{IMAGING EVALUATION OF CEREBRAL EDEMA}

\section{Computed Tomography}

Computed tomography (CT) is the most frequently used diagnostic procedure in acute stroke. It is sensitive to net water changes but not fluid shifts among tissue compartments within the brain parenchyma. Therefore, CT is sensitive to ionic and vasogenic edema but not cytotoxic edema because fluid shifts from the vascular to interstitial spaces during the first two processes $(22,39,40)$. Experimental models have demonstrated a linear relationship between CT attenuation and hemispheric tissue water content (39-41). Within the first few hours following stroke onset, CT shows attenuation of gray matter, which results in the loss of gray/white matter contrast in the cortex, indistinct basal ganglia, and an insular ribbon. With the development of edema, cortical sulci may disappear, and hypoattenuation develops in white matter. During the late stages, ventricles may shrink because of increased parenchymal volume, and MLS occurs.

\section{Midline Shift and Volume of Infarct-Related Hypodensity}

MLS and the volume of infarct-related hypodensity are two commonly used imaging markers of edema based on CT images (16-18). MLS describes the degree of displacement of the septum pellucidum, which is a thin membrane between the frontal horns of the lateral ventricles, relative to the ideal midline on CT images. An MLS of over $5 \mathrm{~mm}$ is usually considered malignant cerebral edema $(18,42)$. Edema in a temporal lobe infarction can cause uncal herniation with severe symptoms despite minimal MLS.

The volume of infarct-related hypodensity has also been widely used to evaluate edema $(22,25)$, and it can be manually outlined on each CT slice. However, quantifying hypodensity on CT during the acute phase when infarcts are subtle can sometimes be difficult; moreover, distinguishing edema from infarct growth in follow-up studies is also challenging.

At present, several comprehensive scores are based on the above methods, such as cerebral edema grading (grade $1=$ focal brain swelling of $\leq 1 / 3$ of the hemisphere, grade $2=>1 / 3$ of the hemisphere, grade $3=$ edema with MLS; Figure 1). These scores are used widely in clinical studies (43-45). However, this semiquantitative method can only be applied to roughly assess the degree of edema, and it is insufficient for evaluating patients with mild edema. 

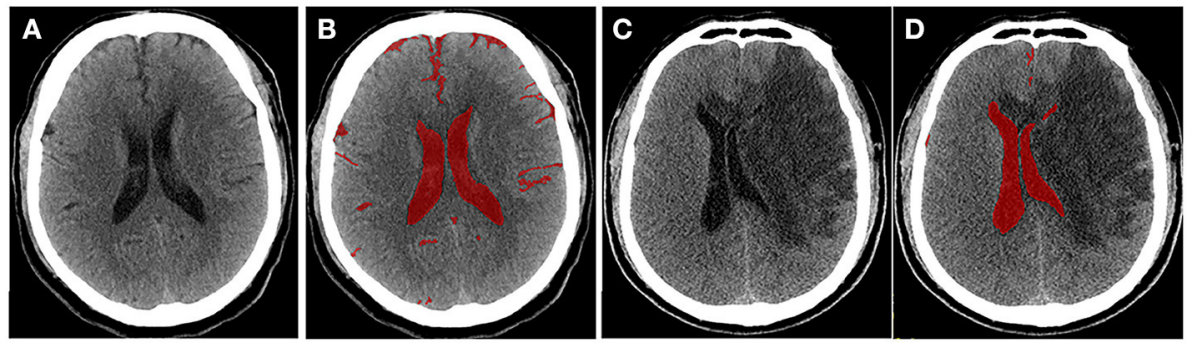

FIGURE 2 | Quantitative cerebrospinal fluid (CSF) shifts. Baseline (A) and $24 \mathrm{~h}$ (C) follow-up CTs after ischemic stroke, respectively. CSF spaces are outlined on a CT scan slice at baseline (B) and follow-up (D). Supratentorial CSF and basal cisterns were outlined on each slice, and $\Delta$ CSF was subsequently calculated.
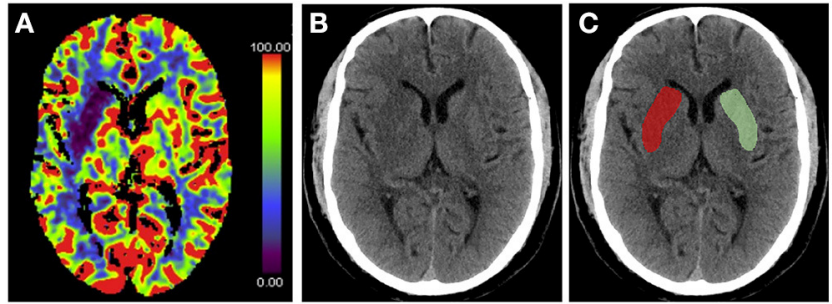

FIGURE 3 | Measurement of \% net water uptake (NWU) per volume on admission. (A) The initial ischemic core is identified by the initial relative cerebral blood flow (CBF) volume using a threshold of $<30 \%$ in CBF maps. (B) Non-enhanced computed tomography shows a slight decrease in the density of the right basal ganglia region. (C) The mean density of the initial core ( $\mathrm{D}_{\text {ischemic }}$ ) (red) was calculated in relation to the normal density ( $\mathrm{D}_{\text {normal }}$ ) (green) in the homotopic contralateral region. $N W U=1-D_{\text {Ischemic }} / D_{\text {Normal. }}$.

\section{Displacement of Cerebrospinal Fluid}

To quantify the severity of edema more accurately, Dhar et al. proposed a CT-based volumetric measure of CSF shifts over time (19). As ionic and vasogenic edemas develop, the CSF is progressively displaced from the sulci and ventricles of the cerebral hemispheres to compensate for the increased brain tissue volume in the fixed cranial cavity. Supratentorial CSF spaces (sulci and ventricles ipsilateral and contralateral to the stroke and the third ventricle) and basal cisterns are outlined on each slice, and the volume of CSF is quantified (Figure 2). The CSF can be pushed out of the hemispheric sulci, cerebral ventricles, and basal cisterns as edema develops in the hours or days following the stroke. Studies have shown that, compared with MLS, the reduction in CSV ( $\triangle \mathrm{CSF}$ ) from baseline to follow-up CT is an earlier and more sensitive indicator of edema severity across a broader dynamic range $(46,47)$. Furthermore, the authors developed an automated algorithm to segment the CSF from the CT scans of stroke patients (46) to facilitate and scale up such approaches. However, their method measures changes in the brain volume (BV); thus, it cannot distinguish edema from infarct growth or hemorrhagic transformation. Moreover, it is not suitable for patients with stroke in the brainstem or cerebellum.

\section{Net Water Uptake}

Recent studies have proposed the use of NWU within the lesion area to determine the volume of edema $(12,48-50)$. NWU is calculated using the equation NWU $=1-\mathrm{D}_{\text {Ischemic }} / \mathrm{D}_{\text {Normal }}$, where $\mathrm{D}_{\text {Ischemic }}$ (Hounsfield Unit, $\mathrm{HU}$ ) is the density of the ischemic core with hypoattenuation, and $\mathrm{D}_{\text {Normal }}$ is the density of the same area in the contralateral normal tissue $(21,49,51)$ (Figure 3). This quantitative method is based on a physical principle in which the product between the volume of a body and its mean CT density remains constant, regardless of the volume of water uptake (49). Therefore, the increased water content is proportional to the NWU, and the edematous component of the infarct lesion can be quantified using CT densitometry according to the following equation: edema volume $=$ lesion volume $\times$ NWU.

CT-based NWU quantification has been described as a precise method to determine the individual volume of edema (21). A previous study demonstrated that it is related to histopathological measurements of the volume of water uptake (52). Fu et al. proposed a new image patch-based NWU procedure that only uses non-enhanced admission CT without the need for lesion segmentation (53). However, this approach has other limitations; for example, patients with pre-existing stroke or significant carotid stenosis may have hypodense lesions, which affect NWU measurement.

\section{Magnetic Resonance Imaging}

Similar to CT, cerebral edema can also be assessed by MLS and change in CSV on MRI because BV increases as edema progresses. Moreover, the intensity characteristics of MRI reflect the tissue composition, and some sequences are particularly sensitive to changes in water content.

\section{T2 and T2 Fluid-Attenuated Inversion Recovery}

T2 prolongation is commonly observed hours after stroke and is considered to be related to increased water content in ischemic tissue, which represents ionic and vasogenic edema $(54,55)$. Gerriets et al. found that a significant T2 signal increase is detectable as early as $20-45 \mathrm{~min}$ following middle cerebral artery occlusion in rats (56). However, in the early phase of stroke, a slightly increased T2 signal intensity may be masked by high CSF signal. Therefore, T2-weighted fluid-attenuated inversion recovery (FLAIR) sequences can be more sensitive because of the inhibition of CSF signals. In several studies, FLAIR hyperintensity has been measured by calculating the intensity ratio between the stroke lesion and the corresponding normal 


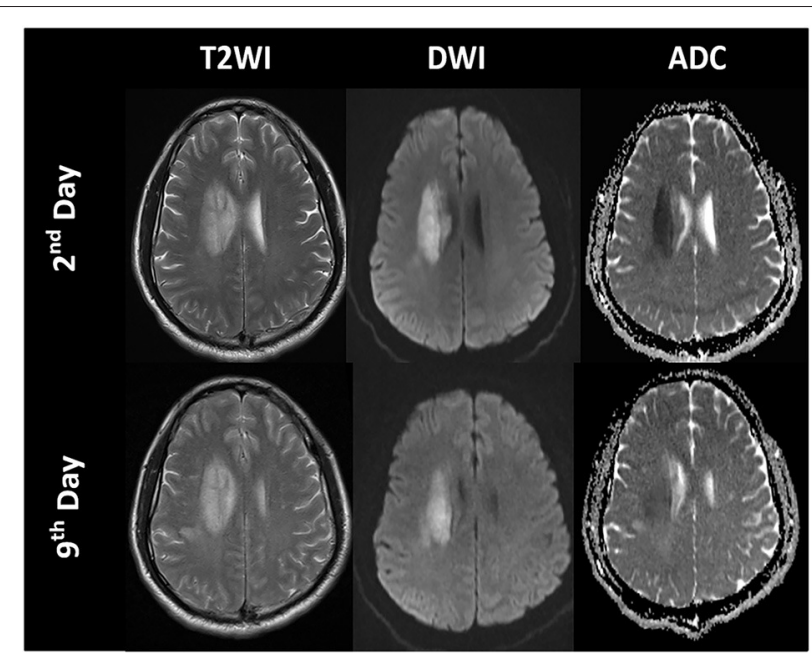

FIGURE 4 | Time course of the signal intensities in T2-weighted imaging (T2WI), diffusion-weighted imaging (DWI), and apparent diffusion coefficient (ADC) maps of a patient with a right paraventricular infarct.

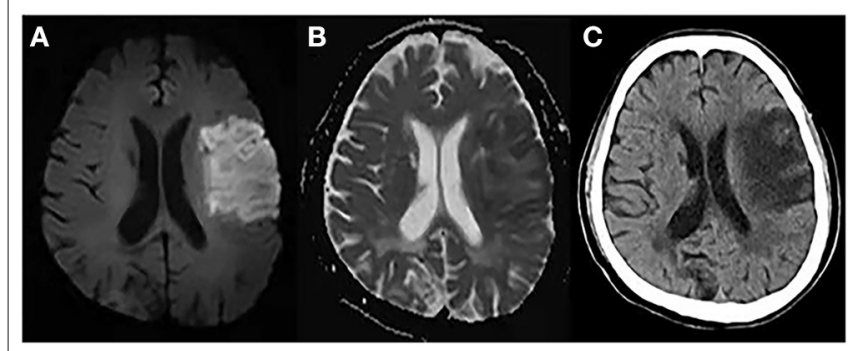

FIGURE 5 | Cytotoxic edema, ionic edema, and vasogenic edema on MRI and CT. A 69-year-old male underwent MRI and CT on day 5 post-stroke. (A) DWI shows hyperintensity in the left frontal and parietal lobes. (B) ADC map shows hypointensity in the marginal area of the lesion, indicating cytotoxic edema, and hyperintensity in the lesion center, indicating ionic and vasogenic edema. (C) CT image shows hypodensity in the left frontal and parietal lobes, especially in the area of ionic and vasogenic edema (i.e., ADC hyperintensity area).

contralateral hemisphere as a marker to quantify vasogenic edema (57-59).

\section{Diffusion Magnetic Resonance Imaging}

Diffusion MRI is sensitive to the diffusion of water molecules in biological tissue and plays a critical role in the research and clinical management of acute stroke. Diffusion-weighted imaging (DWI) is the most frequently used technique to detect cytotoxic edema. An increase in DWI and a decrease in apparent diffusion coefficient (ADC) can be observed several hours after acute ischemia because of extracellular fluid loss and swelling of various cellular compartments, which are proportionate to the degree of intracellular water accumulation $(60,61)$. ADC declines immediately when the cerebral blood flow (CBF) falls below 20 to $40 \mathrm{ml} / 100 \mathrm{~g} / \mathrm{min}$ in animals and humans (22), and the most dominant decay occurs within the first hours (1-1.5 h) $(57,61$, 62). Subsequently, ADC values increase in the days following stroke because of progressive ionic and vasogenic edema and cell lysis, which results in a phenomenon called ADC pseudonormalization (63) (Figures 4, 5). Therefore, timely imaging (24$48 \mathrm{~h}$ after stroke onset) is essential to evaluate the process of cytotoxic edema.

However, DWI provides relatively limited quantitative information regarding the microstructural features of brain tissue. Recently, several advanced diffusion techniques have been proposed, such as the ball-and-stick model, q-ball imaging, diffusion spectrum imaging, composite hindered and restricted models of diffusion, and neurite orientation dispersion and density imaging (NODDI) (64-67). Among these, NODDI provides quantification of the relative contribution of the three diffusion compartments (CSF-like, extra-neurite, and intraneurite) to the total diffusion signal in each voxel (65). NODDI parameters can be used to further elaborate microstructural changes within ischemic tissue and may disentangle the confounding factors behind cerebral edema.

\section{NEUROIMAGING PREDICTORS OF EDEMA}

The measurement methods of edema have been described above. Because edema strongly influences patient prognoses, predicting its occurrence in the early stages is vital to provide timely intervention. To date, various clinical and imaging markers have been developed to predict edema. In this review, we focus on neuroimaging predictors.

\section{Infarction Volume}

A large ischemic core is considered a key risk factor for ME. Occlusion of both the middle cerebral (MCA) and internal carotid arteries (ICA) is a strong predictor of MLS $(11,18,68,69)$. For patients with MCA occlusion, over $50 \%$ of the MCA territory infarction on initial CT predicts ME $(18,70)$, whereas an acute DWI volume of $>80 \mathrm{ml}$ on MRI acquired within $6 \mathrm{~h}$ of stroke onset and that of $>145 \mathrm{ml}$ when imaged $14 \mathrm{~h}$ from stroke onset have been shown to predict rapid early neurological deterioration and the need for neurosurgery $(11,71-74)$.

A large cerebellar hemisphere infarction is the major cause of severe edema in infra-tentorial infarcts and results in acute obstructive hydrocephalus and potentially fatal tonsillar herniation. Decompressive suboccipital craniectomy with dural expansion with or without ventriculostomy leads to acceptable functional outcomes in most patients. However, cerebellar infarction volume that is predictive of the need for decompression has not yet been established $(75,76)$.

The early development of a large ischemic area suggests extensive cytotoxic edema. Because this may be associated with a proximal clot, in combination with a poor leptomeningeal collateral status, it can further lead to prominent vasogenic edema.

\section{Intracranial Volume Reserve}

Intracranial volume reserve is represented by the space occupied by the CSF, which is mainly determined by pre-existing brain atrophy. A larger intracranial volume reserve provides space 
to compensate for the increased $\mathrm{BV}$ and can alleviate early neurological deterioration.

The assessment of BV and/or CSV can quantify the degree of brain atrophy $(72,77,78)$. The DWI high-intensity volume/BV ratio and cerebral blood volume lesion volume/CSV ratio have been demonstrated as reliable predictive markers for malignant MCA infarction, with a cut-off value of 0.078 (sensitivity $86 \%$, specificity $87 \%$ ) and 0.92 (sensitivity $96.2 \%$, specificity $96.2 \%$ ), respectively $(72,79)$. However, BV information is not readily available to clinicians during the management of acute stroke patients because traditional image processing methods involve sophisticated post-processing steps and are thus relatively slow. However, the application of deep learning-based segmentation methods can provide fast and accurate results (47), which offers great potential for future clinical practice.

Intercaudate distance (ICD) is considered a convenient and practical marker for brain atrophy (80), and a higher ICD has been shown to be a protective factor against malignant infarction $(74,78,80)$. Lee et al. demonstrated that an ICD $\geq 20 \mathrm{~mm}$ in the non-infarcted hemisphere has an independent protective effect against malignant clinical outcomes during admission to hospital. However, it is also negatively associated with a modified Rankin Scale score of $<4$ at 6 months (80). These studies indicate that although intracranial volume reserve can compensate for the space-occupying edema during the early phase of stroke, it also represents a pre-existing neurodegenerative process that affects patients' long-term outcomes.

\section{Blood-Brain Barrier Permeability}

The BBB is the interface between blood circulation and brain tissue; it consists of a continuous endothelial membrane within brain microvessels and is sheathed by mural vascular cells and perivascular astrocyte end-feet. During ischemia, several pathological mechanisms, such as inflammation and oxidative stress, can disrupt BBB integrity and increase paracellular permeability, which contributes to vasogenic edema $(81,82)$.

In clinical studies, the permeability of the BBB (BBBP) is usually measured by the amount of contrast agent that leaks into the extravascular space $(83,84)$. Hom et al. analyzed 32 patients with acute anterior circulation stroke within $12 \mathrm{~h}$ of stroke onset and found that BBBP $>7 \mathrm{ml} / 100 \mathrm{~g} / \mathrm{min}$ at admission is $100 \%$ sensitive and $79 \%$ specific in predicting symptomatic hemorrhagic transformation and ME. Moreover, specificity further increases to $100 \%$ after adding age ( $\geq 65$ years) and tissue plasminogen activator (tPA) administration (81). Compared with cerebral hemorrhage, cerebral edema may have a lesser degree of $\mathrm{BBB}$ disruption because it only needs to be permeable to small molecules, such as albumin, rather than blood cells. Unfortunately, the clinical application of BBBP measurement is limited by the use of contrast agents. Recently, a new MRI method based on diffusion-weighted arterial spin labeling (ASL) was proposed as a method to quantify the rate of water exchange across the $\mathrm{BBB}$; it has the advantages of repeatable measurement for longitudinal monitoring and being exempt from the need for a contrast agent $(85,86)$.

\section{Collateral Status}

Robust pial arterial collaterals may temporarily preserve blood flow during stroke, and collateral status has been shown to be related to post-stroke cerebral edema. Various methods have been proposed to evaluate collateral status based on different imaging models, such as the American Society of Interventional and Therapeutic Neuroradiology or Thrombolysis in Cerebral Infarction grades on digital subtraction angiography (87), as well as the Alberta Stroke Program Early CT Score based on CT angiography (88) or CT perfusion (89). Additionally, new methods, such as ASL, have also been introduced (90).

Collateral status has been demonstrated to be a predictor of cerebral edema in ischemic stroke $(91,92)$. Jo et al. reported that a collateral status score of $<2$ strongly predicts malignant cerebral edema [odds ratio (OR): $0.165,95 \%$ confidence interval (CI): 0.064-0.426] (92). Poor collateral status is known to augment the progression of the infarct core and induce more proximal vascular occlusion, which are both associated with brain edema $(93,94)$.

In patients undergoing recanalization, those with initially poor collaterals may develop greater early brain edema and have a higher early edema progression rate (EPR) (1.6\% EPR per one collateral status point) $24 \mathrm{~h}$ after acute ischemic stroke (25, 95). This may result in elevated interstitial pressure, increased resistance of collateral arterioles, and downstream perforating arterioles in the hypoperfused area. Subsequently, ischemic edema may be further aggravated, which results in adverse functional outcomes. Huang et al. found that a low collateral score may be an independent risk factor for the development of malignant cerebral edema after mechanical thrombectomy, especially in patients with successful reperfusion (93).

Therefore, collateral status could be used for the early stratification of adjuvant treatment options after successful vessel recanalization, especially anti-edematous treatment.

\section{Cerebral Veins}

Venous changes in the affected hemisphere after acute ischemic stroke may play a crucial role in determining clinical outcomes $(94,96)$, given that the venous system is responsible for $\sim 70$ $80 \%$ of the cerebral blood volume. Zhang et al. suggested that a lack of superficial middle cerebral vein filling contributes to poor outcomes following thrombolysis and that this indicator predicts edema progression within $24 \mathrm{~h}$ in non-reperfusion patients $(97,98)$. Xia et al. assessed cortical veins (Labbe, sphenoparietal sinus, and the superficial middle cerebral vein) and found that the absence of cortical venous filling is associated with increased brain edema and a higher risk of malignant cerebral edema (OR, 14.68; 95\% CI, 4.03-53.45) (94) regardless of whether patients received reperfusion therapy. The likely pathophysiologic mechanism of these signs is the elevation of venous pressure caused by micro-thrombotic occlusion in venules or endothelium swelling after ischemia $(99,100)$, which may increase fluid leakage into the perivascular space, resulting in brain edema (101). 


\section{Recanalization and Reperfusion}

Recanalization therapies in the hyperacute phase following ischemic stroke, such as intravenous thrombolysis with tPA and endovascular thrombectomy, aim to reopen the occluded artery, which has been unequivocally shown to restore $\mathrm{CBF}$ in salvageable ischemic tissue and reduce patient disability $(102,103)$. However, pre-clinical data using rodent and primate models have indicated that tPA facilitates the development of $\mathrm{BBB}$ damage in acute ischemic stroke by inducing phasic secretion of matrix metalloproteinase-9, and reperfusion injury is observed after the restoration of vascular supply to ischemic lesions. Both of these conditions may augment the development of edema following recanalization therapy $(104,105)$. On the contrary, several studies have demonstrated that thrombolytic therapy and recanalization in the hyperacute phase reduce brain edema by arresting infarct growth and rescuing at-risk ischemic tissue $(18,45,93,106,107)$. Thorén et al. analyzed 22,184 patients who underwent recanalization therapies (intravenous thrombolysis and thrombectomy with or without intravenous thrombolysis) and found that patients who had successful recanalization had a lower cerebral edema grade at $24-36 \mathrm{~h}$ than that of those who did not undergo recanalization (13 vs. 23.6\%; OR: 0.52) (45). Additionally, post-hoc analysis of the Echoplanar Imaging Thrombolytic Evaluation Trial and Mechanical Retrieval and Recanalization of Stroke Clots Using Embolectomy cohorts found that increasing reperfusion is associated with and independently predicts less MLS and a lower swelling volume 3-8 days after stroke onset (107). However, downstream reperfusion is not always achieved even after complete recanalization (called futile recanalization), which is likely related to microvascular obstruction. Nawabi et al. reported that futile recanalization after receiving successful endovascular recanalization (thrombolysis in cerebral infarction scale $2 b / 3$ ) is associated with an elevated edema volume in the follow-up CT $24 \mathrm{~h}$ later (12).

\section{ARTIFICIAL INTELLIGENCE IN THE ASSESSMENT AND PREDICTION OF EDEMA}

Artificial intelligence has been widely used in the segmentation of intracranial tissues. Following the theory that CSF displacement reflects the extent of edema, Chen et al. developed a computer algorithm capable of automatically segmenting CSF from standard clinical CT images to evaluate edema and further

\section{REFERENCES}

1. Kahle KT, Simard JM, Staley KJ, Nahed BV, Jones PS, Sun D, et al. Molecular mechanisms of ischemic cerebral edema: role of electroneutral ion transport. Physiology (Bethesda). (2009) 24:257-65. doi: 10.1152/physiol.00015.2009

2. $\mathrm{Hu} \mathrm{HJ}$, Song M. Disrupted ionic homeostasis in ischemic stroke and new therapeutic targets. J Stroke Cerebrovasc Dis. (2017) 26:270619. doi: 10.1016/j.jstrokecerebrovasdis.2017.09.011 refined this algorithm by training a fully convolutional neural network. This new method automatically performs segmentation of clinical CT images with high concordance to manually obtained measurements and takes $<1$ min per scan (108).

Different types of neural network algorithms have been introduced in the past several decades to predict cerebral edema $(109,110)$. Compared with traditional regression models, these new methods have higher accuracy. However, studies that investigated these models are often conducted in a single center with relatively small sample sizes. Thus, further research is needed to validate these methods.

\section{CONCLUSION}

Severe cerebral edema following ischemic stroke is associated with a poor prognosis if timely intervention is not provided. Neuroimaging is important in the assessment of edema and can be used to evaluate the degree of cerebral edema and quantify edema volume. Using different imaging modalities, a range of neuroimaging indicators to predict edema progression have been offered, although their predictive value varies between studies. Therefore, further research is required to establish evaluation and prediction models of cerebral edema and improve their clinical applicability.

\section{AUTHOR CONTRIBUTIONS}

$\mathrm{XZ}$ conceived and drafted the review with guidance from RZ. RZ and $\mathrm{PH}$ critically revised the manuscript. All authors carefully reviewed the content and approved the final manuscript version for publication.

\section{FUNDING}

This study was supported by the National Natural Science Foundation of China (Grant Nos. 81771820 and 82101987), the Natural Science Foundation of Zhejiang Province (Grant Nos. LSZ19H180001 and LQ20H180015), the China Post-doctoral Science Foundation (Grant No. 2019M662083), the Office of China Post-doctoral Council (Grant No. PC2020117), and the Post-doctoral Science Foundation of Zhejiang Province.

\section{ACKNOWLEDGMENTS}

We thank Sarina Iwabuchi, PhD, from Liwen Bianji (Edanz) (www.liwenbianji.cn) for editing a draft of this manuscript. 
5. Nian K, Harding IC, Herman IM, Ebong EE. Blood-brain barrier damage in ischemic stroke and its regulation by endothelial mechanotransduction. Front Physiol. (2020) 11:605398. doi: 10.3389/fphys.2020.605398

6. Jiang X, Andjelkovic AV, Zhu L, Yang T, Bennett MVL, Chen J, et al. Bloodbrain barrier dysfunction and recovery after ischemic stroke. Prog Neurobiol. (2018) 163-164:144-71. doi: 10.1016/j.pneurobio.2017.10.001

7. Liebeskind DS, Juttler E, Shapovalov Y, Yegin A, Landen J, Jauch EC. Cerebral edema associated with large hemispheric infarction. Stroke. (2019) 50:2619-25. doi: 10.1161/STROKEAHA.118.024766

8. Alquisiras-Burgos I, Ortiz-Plata A, Franco-Perez J, Millan A, Aguilera P. Resveratrol reduces cerebral edema through inhibition of de novo SUR1 expression induced after focal ischemia. Exp Neurol. (2020) 330:113353. doi: 10.1016/j.expneurol.2020.113353

9. Powers WJ, Rabinstein AA, Ackerson T, Adeoye OM, Bambakidis $\mathrm{NC}$, Becker $\mathrm{K}$, et al. Guidelines for the early management of patients with acute ischemic stroke: 2019 update to the 2018 guidelines for the early management of acute ischemic stroke: a guideline for healthcare professionals from the American Heart Association/American Stroke Association. Stroke. (2019) 50:e344-418. doi: 10.1161/STR.0000000000000211

10. Kim H, Jin ST, Kim YW, Kim SR, Park IS, Jo KW. Predictors of malignant brain edema in middle cerebral artery infarction observed on CT angiography. J Clin Neurosci. (2015) 22:55460. doi: 10.1016/j.jocn.2014.08.021

11. Wu S, Yuan R, Wang Y, Wei C, Zhang S, Yang X, et al. Early prediction of malignant brain edema after ischemic stroke. Stroke. (2018) 49:291827. doi: 10.1161/STROKEAHA.118.022001

12. Nawabi J, Flottmann F, Hanning U, Bechstein M, Schon G, Kemmling A, et al. Futile recanalization with poor clinical outcome is associated with increased edema volume after ischemic stroke. Invest Radiol. (2019) 54:2827. doi: 10.1097/RLI.0000000000000539

13. Hofmeijer J, Kappelle LJ, Algra A, Amelink GJ, van Gijn J, van der Worp $\mathrm{HB}$, et al. Surgical decompression for space-occupying hemispheric infarction: a systematic review and individual patient metaanalysis of randomized clinical trials. JAMA Neurol. (2021) 78:20816. doi: 10.1001/jamaneurol.2020.3745

14. Stokum JA, Gerzanich V, Sheth KN, Kimberly WT, Simard JM. Emerging pharmacological treatments for cerebral edema: evidence from clinical studies. Annu Rev Pharmacol Toxicol. (2020) 60:291-309. doi: 10.1146/annurev-pharmtox-010919-023429

15. Reinink H, Juttler E, Hacke W, Hofmeijer J, Vicaut E, Vahedi K, et al. Surgical decompression for space-occupying cerebral infarction (the Hemicraniectomy After Middle Cerebral Artery infarction with Lifethreatening Edema Trial [HAMLET]): a multicentre, open, randomised trial. Lancet Neurol. (2009) 8:326-33. doi: 10.1016/S1474-4422(09)70047-X

16. Barber PA, Demchuk AM, Zhang J, Kasner SE, Hill MD, Berrouschot $\mathrm{J}$, et al. Computed tomographic parameters predicting fatal outcome in large middle cerebral artery infarction. Cerebrovasc Dis. (2003) 16:2305. doi: 10.1159/000071121

17. Ong CJ, Gluckstein J, Laurido-Soto O, Yan Y, Dhar R, Lee JM. Enhanced detection of edema in malignant anterior circulation stroke (EDEMA) score: a risk prediction tool. Stroke. (2017) 48:1969-72. doi: 10.1161/STROKEAHA.117.016733

18. Miao J, Song X, Sun W, Qiu X, Lan Y, Zhu Z. Predictors of malignant cerebral edema in cerebral artery infarction: a meta-analysis. J Neurol Sci. (2020) 409:116607. doi: 10.1016/j.jns.2019.116607

19. Dhar R, Yuan K, Kulik T, Chen Y, Heitsch L, An H, et al. CSF volumetric analysis for quantification of cerebral edema after hemispheric infarction. Neurocrit Care. (2016) 24:420-7. doi: 10.1007/s12028-015-0204-Z

20. Kauw F, Bennink E, de Jong HWAM, Kappelle LJ, Horsch AD, Velthuis BK, et al. Intracranial cerebrospinal fluid volume as a predictor of malignant middle cerebral artery infarction. Stroke. (2019) 50:STROKEAHA119024882. doi: 10.1161/STROKEAHA.119.026853

21. Broocks G, Flottmann F, Ernst M, Faizy TD, Minnerup J, Siemonsen $S$, et al. Computed tomography-based imaging of voxel-wise lesion water uptake in ischemic brain: relationship between density and direct volumetry. Invest Radiol. (2018) 53:207-13. doi: 10.1097/RLI.00000000000 00430
22. von Kummer $\mathrm{R}$, Dzialowski I. Imaging of cerebral ischemic edema and neuronal death. Neuroradiology. (2017) 59:54553. doi: 10.1007/s00234-017-1847-6

23. Obenaus A, Badaut J. Role of the noninvasive imaging techniques in monitoring and understanding the evolution of brain edema. J Neurosci Res. (2021). doi: 10.1002/jnr.24837. [Epub ahead of print].

24. Zhang LJ, Zhong J, Lu GM. Multimodality MR imaging findings of low-grade brain edema in hepatic encephalopathy. AJNR Am J Neuroradiol. (2013) 34:707-15. doi: 10.3174/ajnr.A2968

25. Galego O, Jesus-Ribeiro J, Baptista M, Sargento-Freitas J, Martins AI, Silva F, et al. Collateral pial circulation relates to the degree of brain edema on CT 24 hours after ischemic stroke. Neuroradiol J. (2018) 31:45663. doi: $10.1177 / 1971400918769912$

26. Dhar R, Chen Y, Hamzehloo A, Kumar A, Heitsch L, He J, et al. Reduction in cerebrospinal fluid volume as an early quantitative biomarker of cerebral edema after ischemic stroke. Stroke. (2020) 51:4627. doi: 10.1161/STROKEAHA.119.027895

27. Muscari A, Faccioli L, Lega MV, Lorusso A, Trossello MP, Puddu GM, et al. Predicting cerebral edema in ischemic stroke patients. Neurol Sci. (2019) 40:745-52. doi: 10.1007/s10072-019-3717-y

28. Zhao YX, Cui M, Chen SF, Dong Q, Liu XY. Amelioration of ischemic mitochondrial injury and Bax-dependent outer membrane permeabilization by Mdivi-1. CNS Neurosci Ther. (2014) 20:528-38. doi: 10.1111/cns.12266

29. Yan Y, Dempsey RJ, Flemmer A, Forbush B, Sun D. Inhibition of $\mathrm{Na}(+)-\mathrm{K}(+)-\mathrm{Cl}(-)$ cotransporter during focal cerebral ischemia decreases edema and neuronal damage. Brain Res. (2003) 961:22-31. doi: 10.1016/S0006-8993(02)03832-5

30. O’Donnell ME, Chen YJ, Lam TI, Taylor KC, Walton JH, Anderson SE. Intravenous HOE-642 reduces brain edema and $\mathrm{Na}$ uptake in the rat permanent middle cerebral artery occlusion model of stroke: evidence for participation of the blood-brain barrier $\mathrm{Na} / \mathrm{H}$ exchanger. J Cereb Blood Flow Metab. (2013) 33:225-34. doi: 10.1038/jcbfm.2012.160

31. Vella J, Zammit C, Di Giovanni G, Muscat R, Valentino M. The central role of aquaporins in the pathophysiology of ischemic stroke. Front Cell Neurosci. (2015) 9:108. doi: 10.3389/fncel.2015.00108

32. O’Donnell ME, Tran L, Lam TI, Liu XB, Anderson SE. Bumetanide inhibition of the blood-brain barrier $\mathrm{Na}-\mathrm{K}-\mathrm{Cl}$ cotransporter reduces edema formation in the rat middle cerebral artery occlusion model of stroke. J Cereb Blood Flow Metab. (2004) 24:1046-56. doi: 10.1097/01.WCB.0000130867.32663.90

33. Yuen N, Lam TI, Wallace BK, Klug NR, Anderson SE, O’Donnell ME. Ischemic factor-induced increases in cerebral microvascular endothelial cell $\mathrm{Na} / \mathrm{H}$ exchange activity and abundance: evidence for involvement of ERK1/2 MAP kinase. Am J Physiol Cell Physiol. (2014) 306:C93142. doi: 10.1152/ajpcell.00021.2013

34. Jia SW, Liu XY, Wang SC, Wang YF. Vasopressin hypersecretionassociated brain edema formation in ischemic stroke: underlying mechanisms. J Stroke Cerebrovasc Dis. (2016) 25:1289300. doi: 10.1016/j.jstrokecerebrovasdis.2016.02.002

35. Khatri R, McKinney AM, Swenson B, Janardhan V. Bloodbrain barrier, reperfusion injury, and hemorrhagic transformation in acute ischemic stroke. Neurology. (2012) 79(Suppl. 1):S527. doi: 10.1212/WNL.0b013e3182697e70

36. Yang C, Hawkins KE, Dore S. Candelario-Jalil. Neuroinflammatory mechanisms of blood-brain barrier damage in ischemic stroke. Am J Physiol Cell Physiol. (2019) 316:C135-53. doi: 10.1152/ajpcell.00136.2018

37. Iliff JJ, Wang M, Liao Y, Plogg BA, Peng W, Gundersen GA, et al. A paravascular pathway facilitates CSF flow through the brain parenchyma and the clearance of interstitial solutes, including amyloid beta. Sci Transl Med. (2012) 4:147ra111. doi: 10.1126/scitranslmed.3003748

38. Mestre H, Du T, Sweeney AM, Liu G, Samson AJ, Peng W, et al. Cerebrospinal fluid influx drives acute ischemic tissue swelling. Science. (2020) 367:eaax7171. doi: 10.1126/science.aax7171

39. Dzialowski I, Weber J, Doerfler A, Forsting M, von Kummer R. Brain tissue water uptake after middle cerebral artery occlusion assessed with CT. J Neuroimaging. (2004) 14:42-8. doi: 10.1111/j.1552-6569.2004.tb00214.x

40. Dzialowski I, Klotz E, Goericke S, Doerfler A, Forsting M, von Kummer R. Ischemic brain tissue water content: CT monitoring during middle 
cerebral artery occlusion and reperfusion in rats. Radiology. (2007) 243:7206. doi: 10.1148/radiol.2432060137

41. Nemoto EM, Mendez O, Kerr ME, Firlik A, Stevenson K, Jovin $\mathrm{T}$, et al. CT density changes with rapid onset acute, severe, focal cerebral ischemia in monkeys. Transl Stroke Res. (2012) 3:369-74. doi: 10.1007/s12975-012-0193-6

42. Du M, Huang X, Li S, Xu L, Yan B, Zhang Y, et al. A nomogram model to predict malignant cerebral edema in ischemic stroke patients treated with endovascular thrombectomy: an observational study. Neuropsychiatr Dis Treat. (2020) 16:2913-20. doi: 10.2147/NDT.S279303

43. Strbian D, Meretoja A, Putaala J, Kaste M, Tatlisumak T. Cerebral edema in acute ischemic stroke patients treated with intravenous thrombolysis. Int $J$ Stroke. (2013) 8:529-34. doi: 10.1111/j.1747-4949.2012.00781.x

44. Thoren M, Azevedo E, Dawson J, Egido JA, Falcou A, Ford GA, et al. Predictors for cerebral edema in acute ischemic stroke treated with intravenous thrombolysis. Stroke. (2017) 48:2464-71. doi: 10.1161/STROKEAHA.117.018223

45. Thoren M, Dixit A, Escudero-Martinez I, Gdovinova Z, Klecka L, Rand VM, et al. Effect of recanalization on cerebral edema in ischemic stroke treated with thrombolysis and/or endovascular therapy. Stroke. (2020) 51:21623. doi: 10.1161/STROKEAHA.119.026692

46. Dhar R, Chen Y, An H, Lee JM. Application of machine learning to automated analysis of cerebral edema in large cohorts of ischemic stroke patients. Front Neurol. (2018) 9:687. doi: 10.3389/fneur.2018.00687

47. Dhar R. Automated quantitative assessment of cerebral edema after ischemic stroke using CSF volumetrics. Neurosci Lett. (2020) 724:134879. doi: 10.1016/j.neulet.2020.134879

48. Minnerup J, Broocks G, Kalkoffen J, Langner S, Knauth M, Psychogios $\mathrm{MN}$, et al. Computed tomography-based quantification of lesion water uptake identifies patients within 4.5 hours of stroke onset: a multicenter observational study. Ann Neurol. (2016) 80:924-34. doi: 10.1002/ana.24818

49. Broocks G, Flottmann F, Scheibel A, Aigner A, Faizy TD, Hanning $\mathrm{U}$, et al. Quantitative lesion water uptake in acute stroke computed tomography is a predictor of malignant infarction. Stroke. (2018) 49:190612. doi: 10.1161/STROKEAHA.118.020507

50. Foroushani HM, Hamzehloo A, Kumar A, Chen Y, Heitsch L, Slowik A, et al. Quantitative serial CT imaging-derived features improve prediction of malignant cerebral edema after ischemic stroke. Neurocrit Care. (2020) 33:785-92. doi: 10.1007/s12028-020-01056-5

51. Broocks G, Hanning U, Faizy TD, Scheibel A, Nawabi J, Schon G, et al. Ischemic lesion growth in acute stroke: Water uptake quantification distinguishes between edema and tissue infarct. J Cereb Blood Flow Metab. (2020) 40:823-32. doi: 10.1177/0271678X19848505

52. Flottmann F, Broocks G, Faizy TD, Ernst M, Forkert ND, Grosser M, et al. CT-perfusion stroke imaging: a threshold free probabilistic approach to predict infarct volume compared to traditional ischemic thresholds. Sci Rep. (2017) 7:6679. doi: 10.1038/s41598-017-06882-w

53. Fu B, Qi S, Tao L, Xu H, Kang Y, Yao Y, et al. Image patchbased net water uptake and radiomics models predict malignant cerebral edema after ischemic stroke. Front Neurol. (2020) 11:609747. doi: 10.3389/fneur.2020.609747

54. Ayata AH, Ropper C. Ischaemic brain oedema. J Clin Neurosci. (2002) 9:113-24. doi: 10.1054/jocn.2001.1031

55. Neumann-Haefelin T, Kastrup A, de Crespigny A, Yenari MA, Ringer T, Sun $\mathrm{GH}$, et al. Serial MRI after transient focal cerebral ischemia in rats: dynamics of tissue injury, blood-brain barrier damage, edema formation. Stroke. (2000) 31:1965-72; discussion 1972-63. doi: 10.1161/01.STR.31.8.1965

56. Gerriets $\mathrm{T}$, Walberer $\mathrm{M}$, Ritschel $\mathrm{N}$, Tschernatsch $\mathrm{M}$, Mueller C, Bachmann G, et al. Edema formation in the hyperacute phase of ischemic stroke. Laboratory investigation. $J$ Neurosurg. (2009) 111:1036-42. doi: 10.3171/2009.3.JNS0 81040

57. Schaefer PW. Diffusion-weighted imaging as a problem-solving tool in the evaluation of patients with acute strokelike syndromes. Top Magn Reson Imaging. (2000) 11:300-309. doi: 10.1097/00002142-200010000-00006

58. Kimberly WT, Battey TW, Pham L, Wu O, Yoo AJ, Furie KL, et al. Glyburide is associated with attenuated vasogenic edema in stroke patients. Neurocrit Care. (2014) 20:193-201. doi: 10.1007/s12028-013-9917-z
59. Chang PD, Malone HR, Bowden SG, Chow DS, Gill BJA, Ung TH, et al. A multiparametric model for mapping cellularity in glioblastoma using radiographically localized biopsies. AJNR Am J Neuroradiol. (2017) 38:8908. doi: 10.3174/ajnr.A5112

60. Liu KF, Li F, Tatlisumak T, Garcia JH, Sotak CH, Fisher M, et al. Regional variations in the apparent diffusion coefficient and the intracellular distribution of water in rat brain during acute focal ischemia. Stroke. (2001) 32:1897-905. doi: 10.1161/01.STR.32.8.1897

61. Kuroiwa T, Miyasaka N, Fengyo Z, Yamada I, Nakane M, Nagaoka $\mathrm{T}$, et al. Experimental ischemic brain edema: morphological and magnetic resonance imaging findings. Neurosurg Focus. (2007) 22:E11. doi: $10.3171 /$ foc.2007.22.5.12

62. Kucinski T, Vaterlein O, Glauche V, Fiehler J, Klotz E, Eckert B, et al. Correlation of apparent diffusion coefficient and computed tomography density in acute ischemic stroke. Stroke. (2002) 33:178691. doi: 10.1161/01.STR.0000019125.80118.99

63. Ng FC, Campbell BCV. Imaging after thrombolysis and thrombectomy: rationale, modalities and management implications. Curr Neurol Neurosci Rep. (2019) 19:57. doi: 10.1007/s11910-019-0970-7

64. Yang S, Ghosh K, Sakaie K, Sahoo SS, Carr SJA, Tatsuoka C. A simplified crossing fiber model in diffusion weighted imaging. Front Neurosci. (2019) 13:492. doi: $10.3389 /$ fnins.2019.00492

65. Kamiya K, Hori M, Aoki S. NODDI in clinical research. J Neurosci Methods. (2020) 346:108908. doi: 10.1016/j.jneumeth.2020.108908

66. Caiazzo G, Trojsi F, Cirillo M, Tedeschi G, Esposito F. Q-ball imaging models: comparison between high and low angular resolution diffusionweighted MRI protocols for investigation of brain white matter integrity. Neuroradiology. (2016) 58:209-15. doi: 10.1007/s00234-015-1616-3

67. Assaf Y, Basser J. Composite hindered and restricted model of diffusion (CHARMED) MR imaging of the human brain. Neuroimage. (2005) 27:4858. doi: 10.1016/j.neuroimage.2005.03.042

68. Shimoyama T, Kimura K, Uemura J, Yamashita S, Saji N, Shibazaki K, et al. The DASH score: a simple score to assess risk for development of malignant middle cerebral artery infarction. J Neurol Sci. (2014) 338:1026. doi: 10.1016/j.jns.2013.12.024

69. Song SY, Ahn SY, Rhee JJ, Lee JW, Hur JW, Lee HK. Extent of contrast enhancement on non-enhanced computed tomography after intra-arterial thrombectomy for acute infarction on anterior circulation: as a predictive value for malignant brain edema. J Korean Neurosurg Soc. (2015) 58:3217. doi: $10.3340 / \mathrm{kkns} .2015 .58 .4 .321$

70. Hofmeijer J, Algra A, Kappelle LJ, van der Worp HB. Predictors of lifethreatening brain edema in middle cerebral artery infarction. Cerebrovasc Dis. (2008) 25:176-84. doi: 10.1159/000113736

71. Thomalla G, Hartmann F, Juettler E, Singer OC, Lehnhardt FG, Kohrmann $\mathrm{M}$, et al. Prediction of malignant middle cerebral artery infarction by magnetic resonance imaging within 6 hours of symptom onset: a prospective multicenter observational study. Ann Neurol. (2010) 68:43545. doi: 10.1002/ana.22125

72. Minnerup J, Wersching $\mathrm{H}$, Ringelstein EB, Heindel $\mathrm{W}$, Niederstadt $T$, Schilling $M$, et al. Prediction of malignant middle cerebral artery infarction using computed tomographybased intracranial volume reserve measurements. Stroke. (2011) 42:3403-9. doi: 10.1161/STROKEAHA.111.619734

73. Park J, Goh DH, Sung JK, Hwang YH, Kang DH, Kim Y, et al. Timely assessment of infarct volume and brain atrophy in acute hemispheric infarction for early surgical decompression: strict cutoff criteria with high specificity. Acta Neurochir (Wien). (2012) 154:7985. doi: 10.1007/s00701-011-1178-z

74. Park, JH, Hwang J. Where are we now with decompressive hemicraniectomy for malignant middle cerebral artery infarction? J Cerebrovasc Endovasc Neurosurg. (2013) 15:61-6. doi: 10.7461/jcen.2013.15.2.61

75. Ayling OGS, Alotaibi NM, Wang JZ, Fatehi M, Ibrahim GM, Benavente $\mathrm{O}$, et al. Suboccipital decompressive craniectomy for cerebellar infarction: a systematic review and meta-analysis. World Neurosurg. (2018) 110:4509.e455. doi: 10.1016/j.wneu.2017.10.144

76. Wijdicks EF, Sheth KN, Carter BS, Greer DM, Kasner SE, Kimberly WT, et al. Recommendations for the management of cerebral and cerebellar infarction with swelling: a statement for healthcare 
professionals from the American Heart Association/American Stroke Association. Stroke. (2014) 45:1222-38. doi: 10.1161/01.str.0000441965.15 164.d6

77. Beck C, Kruetzelmann A, Forkert ND, Juettler E, Singer OC, Kohrmann M. A simple brain atrophy measure improves the prediction of malignant middle cerebral artery infarction by acute DWI lesion volume. J Neurol. (2014) 261:1097-103. doi: 10.1007/s00415-0147324-9

78. Tschirret O, Moreno Legast G, Mansuy A, Mewton N, Buisson M, Hannoun S, et al. Impact of brain atrophy on early neurological deterioration and outcome in severe ischemic stroke treated by intravenous thrombolysis. Eur Neurol. (2018) 79:240-6. doi: 10.1159/0004 87668

79. Goto Y, Kumura E, Watabe T, Nakamura H, Nishino A, Koyama $\mathrm{T}$, et al. Prediction of malignant middle cerebral artery infarction in elderly patients. J Stroke Cerebrovasc Dis. (2016) 25:1389-95. doi: 10.1016/j.jstrokecerebrovasdis.2015. 12.034

80. Lee SH, Oh CW, Han JH, Kim CY, Kwon OK, Son YJ, et al. The effect of brain atrophy on outcome after a large cerebral infarction. J Neurol Neurosurg Psychiatry. (2010) 81:1316-21. doi: 10.1136/jnnp.2009.197335

81. Hom J, Dankbaar JW, Soares BP, Schneider T, Cheng SC, Bredno J, et al. (2011)Blood-brain barrier permeability assessed by perfusion CT predicts symptomatic hemorrhagic transformation and malignant edema in acute ischemic stroke. AJNR Am J Neuroradiol 32:41-8. doi: 10.3174/ajnr. A2244

82. Bektas H, Wu TC, Kasam M, Harun N, Sitton CW, Grotta JC, et al. Increased blood-brain barrier permeability on perfusion CT might predict malignant middle cerebral artery infarction. Stroke. (2010) 41:253944. doi: 10.1161/STROKEAHA.110.591362

83. Kim T, Koo J, Kim SH, Song IU, Chung SW, Lee KS. Blood-brain barrier permeability assessed by perfusion computed tomography predicts hemorrhagic transformation in acute reperfusion therapy. Neurol Sci. (2018) 39:1579-84. doi: 10.1007/s10072-018-3468-1

84. Suh CH, Jung SC, Cho SJ, Kim D, Lee JB, Woo DC, et al. Perfusion CT for prediction of hemorrhagic transformation in acute ischemic stroke: a systematic review and meta-analysis. Eur Radiol. (2019) 29:407787. doi: 10.1007/s00330-018-5936-7

85. Shao X, Ma SJ, Casey M, D’Orazio L, Ringman JM, Wang DJJ. Mapping water exchange across the blood-brain barrier using 3D diffusion-prepared arterial spin labeled perfusion MRI. Magn Reson Med. (2019) 81:306579. doi: $10.1002 / \mathrm{mrm} .27632$

86. Tiwari YV, Lu J, Shen Q, Cerqueira B, Duong TQ. Magnetic resonance imaging of blood-brain barrier permeability in ischemic stroke using diffusion-weighted arterial spin labeling in rats. J Cereb Blood Flow Metab. (2017) 37:2706-15. doi: 10.1177/0271678X16673385

87. Singer OC, Berkefeld J, Nolte CH, Bohner G, Reich A, Wiesmann M, et al. Collateral vessels in proximal middle cerebral artery occlusion: the ENDOSTROKE study. Radiology. (2015) 274:851-8. doi: 10.1148/radiol.141 40951

88. Seker F, Potreck A, Mohlenbruch M, Bendszus M, Pham M. Comparison of four different collateral scores in acute ischemic stroke by CT angiography. J Neurointerv Surg. (2016) 8:1116-8. doi: 10.1136/neurintsurg-2015012101

89. Consoli A, Andersson T, Holmberg A, Verganti L, Saletti A, Vallone S, et al. CT perfusion and angiographic assessment of pial collateral reperfusion in acute ischemic stroke: the CAPRI study. $J$ Neurointerv Surg. (2016) 8:1211-6. doi: 10.1136/neurintsurg-2015-0 12155

90. Lou X, Yu S, Scalzo F, Starkman S, Ali LK, Kim D, et al. Multidelay ASL can identify leptomeningeal collateral perfusion in endovascular therapy of ischemic stroke. Oncotarget. (2017) 8:2437-43. doi: 10.18632/oncotarget.13898

91. Flores A, Rubiera M, Ribo M, Pagola J, Rodriguez-Luna D, Muchada M, et al. Poor collateral circulation assessed by multiphase computed tomographic angiography predicts malignant middle cerebral artery evolution after reperfusion therapies. Stroke. (2015) 46:3149-53. doi: 10.1161/STROKEAHA.115.010608
92. Jo K, Bajgur SS, Kim H, Choi HA, Huh PW, Lee $\mathrm{K}$, et al. A simple prediction score system for malignant brain edema progression in large hemispheric infarction. PLoS ONE. (2017) 12:e0171425. doi: 10.1371/journal.pone.0171425

93. Huang $X$, Yang $Q$, Shi $X, X u$ X, Ge L, Ding X, et al. Predictors of malignant brain edema after mechanical thrombectomy for acute ischemic stroke. J Neurointerv Surg. (2019) 11:994-8. doi: 10.1136/neurintsurg-201814650

94. Xia H, Sun H, He S, Zhao M, Huang W, Zhang Z, et al. Absent cortical venous filling is associated with aggravated brain edema in acute ischemic stroke. AJNR Am J Neuroradiol. (2021) 42:1023-9. doi: 10.3174/ajnr. A7039

95. Broocks G, Kemmling A, Meyer L, Nawabi J, Schon G, Fiehler J, et al. Computed tomography angiography collateral profile is directly linked to early edema progression rate in acute ischemic stroke. Stroke. (2019) 50:3424-30. doi: 10.1161/STROKEAHA.119.027062

96. Chen CY, Chen CI, Tsai FY, Tsai PH, Chan WP. Prominent vessel sign on susceptibility-weighted imaging in acute stroke: prediction of infarct growth and clinical outcome. PLOS ONE. (2015) 10:e0131118. doi: 10.1371/journal.pone.0131118

97. Zhang S, Lai Y, Ding X, Parsons M, Zhang JH, Lou M. absent filling of ipsilateral superficial middle cerebral vein is associated with poor outcome after reperfusion therapy. Stroke. (2017) 48:907-14. doi: 10.1161/STROKEAHA.116.016174

98. Zhang S, Lin L, Zhang R, Wang M, Yu Y, Shi Z, et al. Absent contrast filling of ipsilateral superficial middle cerebral vein predicts midline shift in acute middle cerebral artery occlusion. Front Neurol. (2020) 11:570844. doi: 10.3389/fneur.2020.570844

99. Zhou Y, Wang Y, Wang J, Anne Stetler R, Yang QW. Inflammation in intracerebral hemorrhage: from mechanisms to clinical translation. Prog Neurobiol. (2014) 115:25-44. doi: 10.1016/j.pneurobio.2013. 11.003

100. Schwarzmaier SM, Kim SW, Trabold R, Plesnila N. Temporal profile of thrombogenesis in the cerebral microcirculation after traumatic brain injury in mice. J Neurotrauma. (2010) 27:121-30. doi: 10.1089/neu.2009.1114

101. Alperin N. MR-intracranial compliance and pressure: a method for noninvasive measurement of important neurophysiologic parameters. Methods Enzymol. (2004) 386:323-49. doi: 10.1016/S0076-6879(04)86016-6

102. Emberson J, Lees KR, Lyden P, Blackwell L, Albers G, Bluhmki E, et al. Effect of treatment delay, age, and stroke severity on the effects of intravenous thrombolysis with alteplase for acute ischaemic stroke: a meta-analysis of individual patient data from randomised trials. Lancet. (2014) 384:192935. doi: 10.1016/S0140-6736(14)60584-5

103. Goyal M, Menon BK, van Zwam WH, Dippel DW, Mitchell PJ, Demchuk $\mathrm{AM}$, et al. Endovascular thrombectomy after large-vessel ischaemic stroke: a meta-analysis of individual patient data from five randomised trials. Lancet. (2016) 387:1723-31. doi: 10.1016/S0140-6736(16)00163-X

104. Ning $M$, Furie KL, Koroshetz WJ, Lee H, Barron M, Lederer $M$, et al. Association between tPA therapy and raised early matrix metalloproteinase-9 in acute stroke. Neurology. (2006) 66:1550-5. doi: 10.1212/01.wnl.0000216133.98416.b4

105. Pillai DR, Dittmar MS, Baldaranov D, Heidemann RM, Henning EC, Schuierer G, et al. Cerebral ischemia-reperfusion injury in rats-a $3 \mathrm{~T}$ MRI study on biphasic blood-brain barrier opening and the dynamics of edema formation. J Cereb Blood Flow Metab. (2009) 29:184655. doi: 10.1038/jcbfm.2009.106

106. Kimberly WT, Dutra BG, Boers AMM, Alves, H.cbr, Berkhemer OA, et al. Association of reperfusion with brain edema in patients with acute ischemic stroke: a secondary analysis of the MR CLEAN trial. JAMA Neurol. (2018) 75:453-61. doi: 10.1001/jamaneurol.2017.5162

107. Irvine HJ, Ostwaldt AC, Bevers MB, Dixon S, Battey TW, Campbell BC, et al. Reperfusion after ischemic stroke is associated with reduced brain edema. J Cereb Blood Flow Metab. (2018) 38:1807-17. doi: 10.1177/0271678X177 20559

108. Chen Y, Dhar R, Heitsch L, Ford A, Fernandez-Cadenas I, Carrera C, et al. Automated quantification of cerebral edema following hemispheric infarction: application of a machinelearning algorithm to evaluate CSF shifts on serial head CTs. 
Neuroimage Clin. (2016) 12:673-80. doi: 10.1016/j.nicl.2016. 09.018

109. Wei H, Tang X, Zhang M, Li Q, Xing X, Sean Zhou X, et al. The delineation of largely deformed brain midline using regression-based line detection network. Med Phys. (2020) 47:5531-42. doi: 10.1002/mp. 14302

110. Foroushani HM, Hamzehloo A, Kumar A, Chen Y, Heitsch L, Slowik A, et al. Accelerating prediction of malignant cerebral edema after ischemic stroke with automated image analysis and explainable neural networks. Neurocrit Care. (2021). 20:1-2. doi: 10.1007/s12028-021-01325-x

Conflict of Interest: The authors declare that the research was conducted in the absence of any commercial or financial relationships that could be construed as a potential conflict of interest.
Publisher's Note: All claims expressed in this article are solely those of the authors and do not necessarily represent those of their affiliated organizations, or those of the publisher, the editors and the reviewers. Any product that may be evaluated in this article, or claim that may be made by its manufacturer, is not guaranteed or endorsed by the publisher.

Copyright (c) 2022 Zhang, Huang and Zhang. This is an open-access article distributed under the terms of the Creative Commons Attribution License (CC BY). The use, distribution or reproduction in other forums is permitted, provided the original author(s) and the copyright owner(s) are credited and that the original publication in this journal is cited, in accordance with accepted academic practice. No use, distribution or reproduction is permitted which does not comply with these terms. 